\title{
SIMULATION ANALYSIS OF SHUTTLE BASED STORAGE AND RETRIEVAL SYSTEMS
}

\author{
Lerher, T. ${ }^{*}$; Ekren, Y. B. ${ }^{* *}$; Sari, Z. ${ }^{* * *} \&$ Rosi, B. \\ *University of Maribor, Faculty of Logistics, Mariborska cesta 7, 3000 Celje, Slovenia \\ ${ }^{* *}$ Izmir University of Economics, Department of Industrial Engineering, Izmir, 35330, Turkey \\ ${ }^{* * *}$ University of Tlemcen, Manufacturing Engineering Laboratory of Tlemcen, 13000 Tlemcen, \\ Algeria \\ E-Mail: tone.lerher@um.si, banu.ekren@izmirekonomi.edu.tr, zaki_sari@yahoo.com, \\ bojan.rosi@uni-mb.si
}

\begin{abstract}
In this paper, a simulation-based performance evaluation of shuttle-based storage and retrieval system (SBS/RS) is presented. In comparison with well-known automated storage and retrieval systems, SBS/RSs can substantially increase the throughput capacity of the system. The objective of this study is to exploit the benefits of SBS/RS system design for reducing the mean cycle time of transactions and consequently increasing the throughput capacity of the system. Performance comparison of the studied SBS/RS is contrasted with alternative storage rack configurations, velocity profiles of the shuttle carriers and velocity profiles of the elevators' lifting tables in the system. The results show that SBS/RSs are effective in reducing the mean cycle time and also show large improvement by increasing throughput capacity.

(Received in January 2014, accepted in October 2014. This paper was with the authors 3 months for 2 revisions.)
\end{abstract}

Key Words: Automated Warehouse, Shuttle Based Storage and Retrieval System, Discrete Event Simulation, Performance Analysis

\section{INTRODUCTION}

Automated Storage and Retrieval Systems (AS/RSs) have been widely used in warehouses since 1950 s to store and retrieve unit-loads without interference of an operator. The main advantages of AS/RSs are savings in labour costs and floor space, increased reliability, and reduced error rates.

The main disadvantages are high investment costs, less flexibility, and higher investments in control systems [1]. The early version of an AS/RS is also known as Crane Based Automated Storage and Retrieval Systems (CBAS/RS) which has one Storage and Retrieval $(\mathrm{S} / \mathrm{R})$ machine in each aisle that cannot leave its designated aisle (aisle-captive system). It can transport only one load at a time. There is large number of system design options for AS/RS in the literature $[2,3]$.

Due to increasingly small order sizes with large product variety and faster deliveries, material handling providers are developing new solutions. To meet this demand in throughput and constraints with regard to delivery times in warehouses, SBS/RS is developed in automated material handling industry.

This new technology is developed as an alternative to mini-load CBAS/RS where it cannot handle the required throughput capacity. In this technology, mostly two elevators lifting tables capable of vertical movement of loads (totes) share a single mast to transport totes from horizontally operating shuttle carriers to input/output (I/O) locations and vice versa. Shuttle carriers are usually tier-captive, however some other designs with shuttle carriers traveling between tiers and aisles may also be considered. In this study, we consider an SBS/RS with the tier-captive shuttle carriers. 


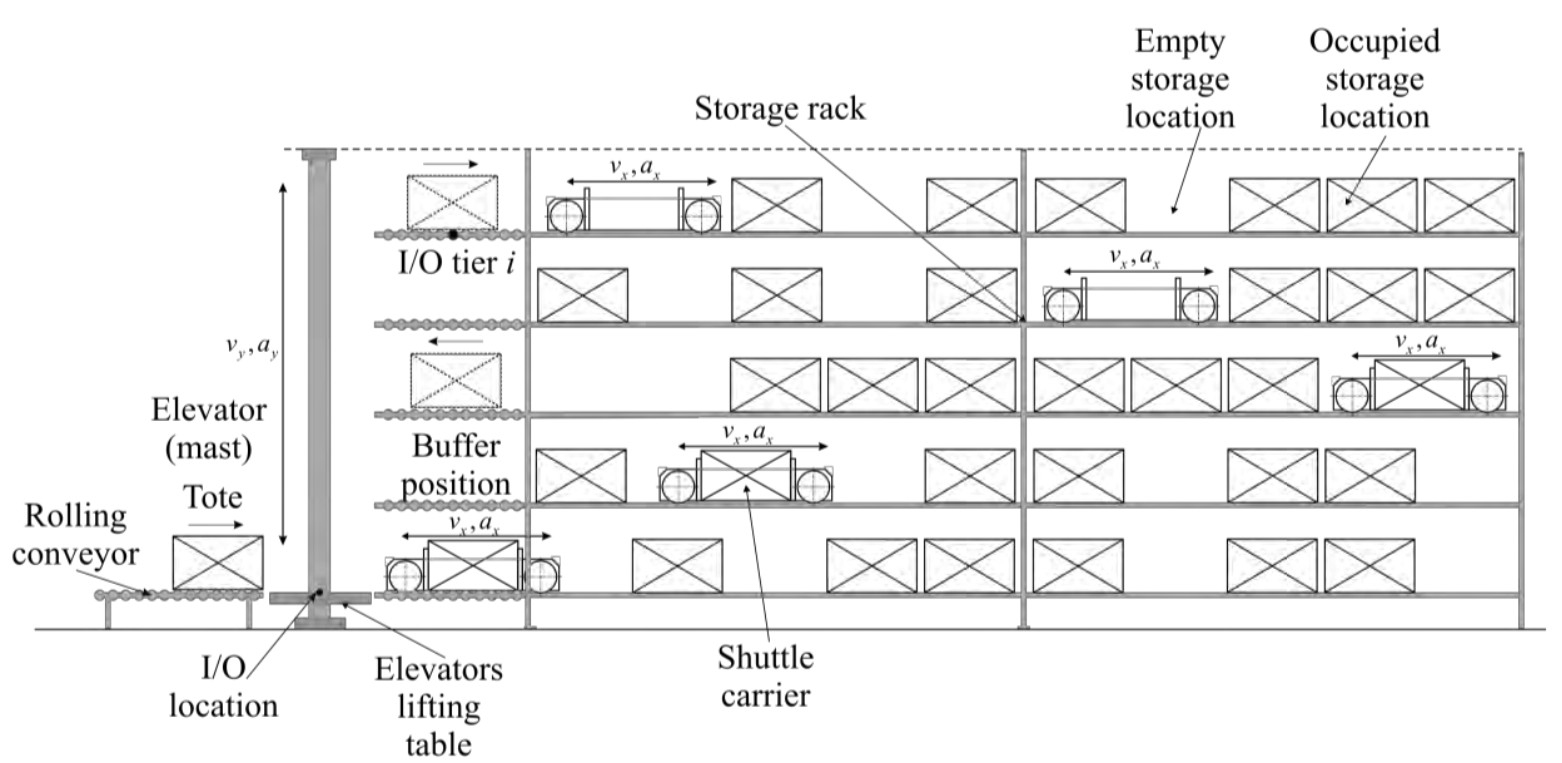

Figure 1: Shuttle based storage and retrieval system.

The purpose of this paper is to evaluate throughput performance of an SBS/RS using simulation. The performance of the studied SBS/RS is evaluated in terms of average cycle time (for dual command), which is expressed by the system throughput capacity.

The remainder of the paper is organized as follows. In section 2, an extensive literature review is presented. In section 3, SBS/RS along with the simulation model is presented. In section 4, SBS/RS design scenarios are presented. Analyses of simulation results and detailed discussions are presented in Chapter 5. Finally, in Section 6, we provide main conclusions from this study.

\section{LITERATURE REVIEW}

Warehouses in supply chain are moving beyond CBAS/RS technologies towards autonomous vehicle-based storage and retrieval system (AVS/RS) technologies offering additional flexibility in warehouse operations [4]. In this technology, throughput capacity can be varied by changing the number of autonomous vehicles (AVs) in the system. The main components of an AVS/RS are lifts and AVs in the rack area. Lifts provide vertical movement for transactions to travel among tiers and AVs provide horizontal movement for transaction within the tier. It has to be emphasized that AVS/RS is introduced for heavy unit-load transactions [4]. In the literature relatively a lot of papers focus on AVS/RS [4-13].

SBS/RS is relatively a new technology in AVS/RS and usually works with aisle and tier captive shuttles. This new technology is mostly used for mini-load warehouses. There are few studies considering this system in the literature.

A first study on SBS/RS is completed by Carlo and Vis [14]. They study an SBS/RS developed by the Vanderlande Industries where two non-passing lifting systems are mounted along the rack. In that paper, they focus on the scheduling problem of lifts where two (piecewise linear) functions are introduced to evaluate candidate solutions. They develop an integrated look-ahead heuristic for the solution procedure to improve the total handling time (in terms of throughput).

Marchet et al. [15] models an SBS/RS via open queuing network to estimate the performance of the system in terms of utilization of lifts and shuttles as well as waiting times for lifts and queues. To validate the analytical models, they utilize simulation modelling. The developed analytical models demonstrate good estimates for the performance measures. Later, Marchet et al. [16] present main design trade-offs for SBS/RS using simulation. They 
complete their study for several warehouse design scenarios for tier captive shuttle vehicles. They present several performance measures from the system - utilizations of lifts and shuttles, average flow time, waiting times as well as cost - for the pre-defined rack designs.

Recently, Lerher et al. [17] and Lerher [18] have studied SBS/RS by considering energy efficiency concept in the system design. The proposed models provide several warehouse designs and their performances. Designs are considered in terms of velocity profiles of lift and shuttle carriers while performances are considered as amount of energy (electricity) consumption, amount of $\mathrm{CO}_{2}$ oscillation and throughput capacity. These studies provide significant contribution in automated warehouse planning by taking into consideration the environment friendly design concept.

Smew at al. [19] presented a simulation study to trade-off between the conflicting objectives of maximising customer service level and minimising Work-In-Process.

Bekker [20] proposed as a computationally economic approach to optimise throughout rate and allocated buffer space, which are the two conflicting objectives of the buffer allocation problem.

Berlec et al. [21] study the calculation of optimal batch quantity using first the basic model, and then the extended model taking into account the tied-up capital in a production, in addition to the costs of changing the batch and storage costs. They implement the study for a case to find out when either of the two models should be used.

Erkan and Can [22] used AHP (Analytic Hierarchy Process) and FAHP (Fuzzy Analytic Hierarchy Process) to decide on Barcode or RFID system to select for a company, in order to collect data for its warehouse. As a result of the study, it is found that AHP produces consistent results with FAHP. Barcode system is selected for the data collection system and FAHP is found to be more sufficient in decision making process due to its fuzziness and vagueness compared to AHP. Unlike the existing studies, we approach to the SBS/RS from a storage rack design and velocity profiles for shuttle carriers and elevators' lifting tables perspective by using simulation modelling.

\section{SHUTTLE BASED STORAGE AND RETRIEVAL SYSTEMS}

SBS/RSs are composed of elevators with lifting tables that are attached on a mast, shuttle carriers, buffer positions and the storage racks (Fig. 1). The elevators lifting table provides vertical movement for totes to reach the prescribed tier in the system. The elevators lifting table can reach up to $1.5 \mathrm{~m} / \mathrm{s}$ velocity and more, theoretically. Elevators are usually bottlenecks in the system so that they determine the performance of the whole system [18].

A shuttle carrier is a tier-captive autonomous vehicle with four wheels that transports totes from buffer position to storage locations in the storage rack. It is equipped with telescopic attachment for manipulating totes. The maximal weight of a tote should not exceed $50 \mathrm{~kg}$ per shuttle carrier and its dimensions should be in the range of: min. $(150 \times 200 \times 80) \mathrm{mm}$ and max. $(600 \times 400 \times 250) \mathrm{mm}$. A shuttle carrier can travel up to $4 \mathrm{~m} / \mathrm{s}$ theoretically.

In SBS/RS, there is usually a single shuttle carrier in each tier of the storage rack (tiercaptive system). This assumption can be released if we use a special shuttle elevator at the back of the storage rack, for moving shuttle carriers up and down to the prescribed tier in the storage rack (tier-to-tier system) [18]. There are two buffer positions, each serving one side in storage rack at each tier. These positions are used for buffering totes carried by lifts for storage process and by shuttles for retrieval process. The storage rack is composed of storage Columns $(C)$. By multiplying storage columns $C$ in the horizontal and Tiers $(T)$ in the vertical direction, the length $L_{S R}$ and the height $H_{S R}$ of the Storage Rack (SR) are achieved.

In continuation, the following assumptions and notations are considered in the simulation model of the SBS/RS. 


\subsection{Main assumptions}

- The SBS/RS is divided into two sides in an aisle. Hence, totes can be stored in either side of a tier.

- The I/O location of the SBS/RS is located at the first tier, next to the lift location (Fig. 1).

- The storage rack is divided by columns and tiers. At each tier, there are two buffer positions (left and right) and a single shuttle carrier (aisle-captive system).

- The elevator manipulates two lifting tables independently one of which is located at the left side and the other one is located at the right side of the elevator. Each lifting table can serve one tote at a time (Fig. 1).

- The elevator and the shuttle carrier complete single and/or dual command cycles.

- Drive characteristics $\left(v_{y}, a_{y}\right)$ of the elevator lifting table as well as the height $H_{S R}$ of the storage rack are known priori.

- Drive characteristics of the shuttle carrier $\left(v_{x}, a_{x}\right)$ as well as the length $L_{S R}$ of the storage racks are known priori.

- The height $H_{S R}$ and the length $L_{S R}$ of the storage racks are large enough for the elevators lifting table and the shuttle carrier to reach their maximum velocity $v_{\max }$ in the vertical and in the horizontal direction.

- Randomized assignment policy is considered, which means that any available storage position in the SBS/RS is equally likely to be selected for storage or retrieval location to be processed.

\section{Notations}

$\begin{array}{ll}\text { AS/RS } & \text { Automated storage and retrieval systems. } \\ \text { CB } & \text { Crane based. } \\ \text { S/R } & \text { Storage and retrieval. } \\ \text { SR } & \text { Storage rack. } \\ \text { CBAS/RS } & \text { Crane based automated storage and retrieval systems. } \\ \text { SBS/RS } & \text { Shuttle based storage and retrieval systems. } \\ \text { I/O } & \text { Input and output. } \\ \text { CO } & \text { Carbon dioxide. } \\ \text { AVS/RS } & \text { Autonomous vehicle storage and retrieval systems. } \\ \mathrm{SC} & \text { Single command cycle. } \\ \text { DC } & \text { Dual command cycle. } \\ \text { vp } & \text { Velocity profile. } \\ \text { AHP } & \text { Analytic hierarchy process. } \\ \text { FAHP } & \text { Fuzzy analytic hierarchy process. } \\ \text { RFID } & \text { Radio frequency identification. } \\ C & \text { Number of columns in the SR. } \\ T & \text { Number of tiers in the SR. } \\ A & \text { Number of aisles in the SR. } \\ L_{S R} & \text { Length of the storage rack. } \\ H_{S R} & \text { Height of the storage rack. } \\ a_{y} & \text { Acceleration / deceleration of the elevators lifting table in the vertical direction. } \\ a_{x} & \text { Acceleration / deceleration of the shuttle carrier in the horizontal direction. } \\ v_{y} & \text { Maximum velocity of the elevators lifting table in the vertical direction. } \\ v_{x} & \text { Maximum velocity of the shuttle carrier in the horizontal direction. } \\ v_{\max } & \text { Maximum velocity. } \\ S & \text { Set of totes to be stored. } \\ R & \text { Set of totes to be retrieved. } \\ \end{array}$




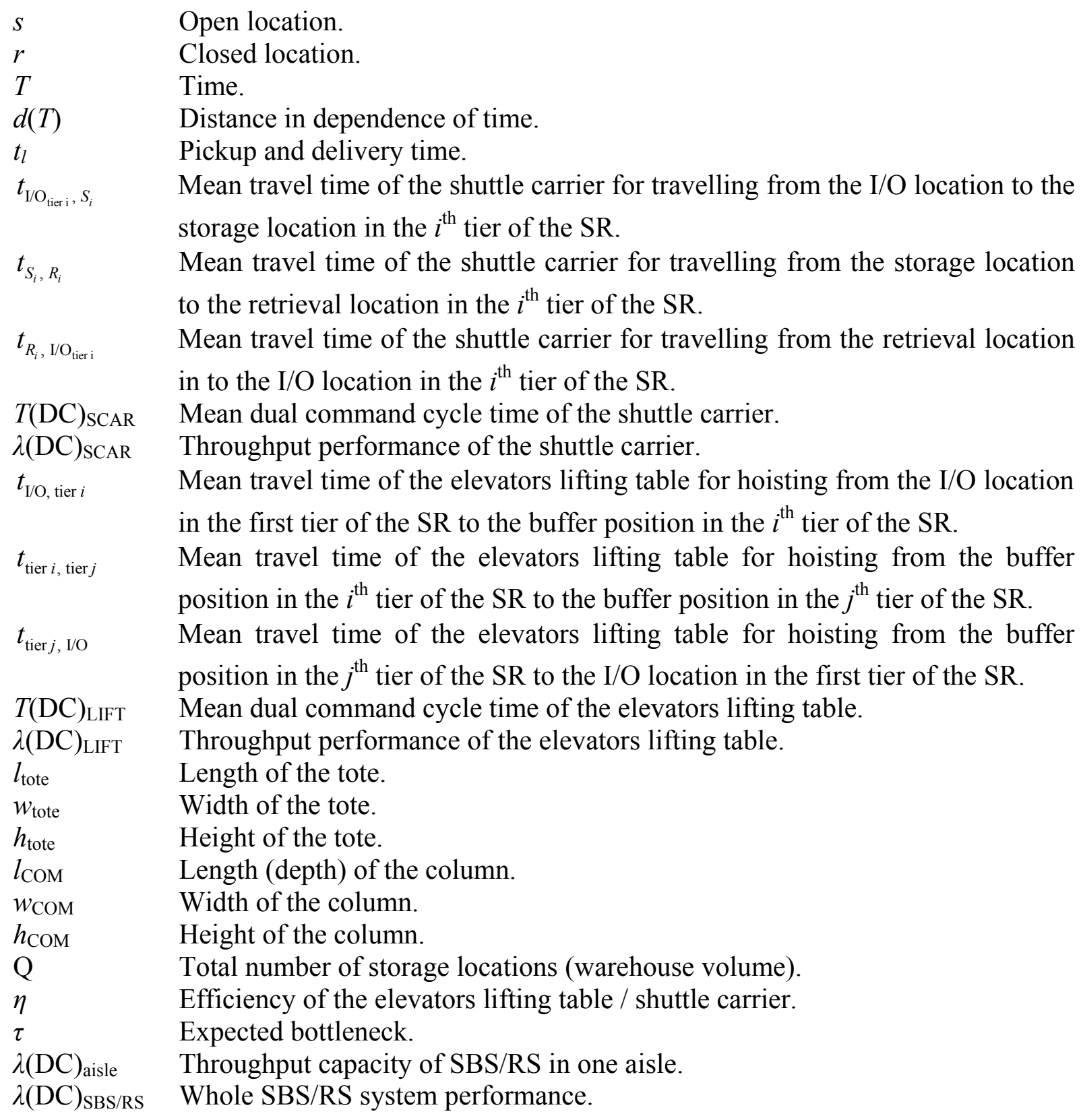

\subsection{Simulation model of the SBS/RS}

To facilitate the performance evaluation of the SBS/RS, discrete event simulation is employed. Our simulation model begins with the process which marks the whole storage locations in the SBS/RS according to the prescribed storage area. After creating the list of free storage locations, enter in the simulation model the first tote, which is situated in the $\mathrm{I} / \mathrm{O}$ location of the SBS/RS. Further on, the tote receives a sign, which belongs to the buffer position in the $i^{\text {th }}$ tier and the storage location in the storage rack of the $i^{\text {th }}$ tier. The elevators lifting table picks up the tote from the I/O location and moves to the buffer position in the $i^{\text {th }}$ tier. After conducting transport to the buffer location in the $i^{\text {th }}$ tier, the elevators lifting table set down the tote, which is waiting to be moved by a shuttle carrier. Next, the shuttle carrier picks up the tote from the buffer position in the $i^{\text {th }}$ tier and travels to the storage location, where the tote is set down by a shuttle carrier. For the storage operation, the randomized storage policy has been used. Next, the tote stored is put on the waiting list by a computer (computer data base), where it waits for the retrieval operation. For the retrieval process the random request selection rule has been used. 
After the storage operation in the $i^{\text {th }}$ tier, the shuttle carrier travels to the retrieval location in the $i^{\text {th }}$ tier of the storage rack. The retrieval location is positioned in the same tier (tiercaptive system). Next, the shuttle carrier picks up the tote and moves through the tier to the buffer position in the $i^{\text {th }}$ tier, where the tote is next picked up by the elevators lifting table.

The average cycle time for the transaction is therefore associated with the travel time of the elevators lifting table and the travel time of the shuttle carrier. As a performance measure for the SBS/RS, the mean Dual Command (DC) cycle time and consequently the throughput capacity have been used. The throughput capacity represents the number of transactions (stores and retrievals) that the system can perform in a given time period. As a note, the throughput capacity is inversely dependent on the average cycle time.

Movement of the elevators lifting table and travelling of the shuttle carrier in the simulation model is based on the real velocity-time dependence. Two types of velocity-time dependences can be distinguished depending on whether the obtained peak velocity $v\left(t_{p}\right)$ is less than $v_{\max }$ (type I) or equal to $v_{\max }$ (type II). It can be verified that time $T<2 v_{\max } / a$ for type I and $T>2 v_{\max } / a$ for type II.

\section{Velocity-time dependence for type I}

The distance in dependence of time $d(T)$ equals the following expression:

$$
d(T)=\int_{0}^{T} v(t) d t=\frac{a \cdot T^{2}}{4}
$$

\section{Velocity-time dependence for type II}

The distance in dependence of time $d(T)$ equals the following expression:

$$
d(T)=\int_{0}^{T} v(t) d t=v_{\max } \cdot T-\frac{v_{\max }^{2}}{a}
$$

\section{The definition of the storage strategy}

As mentioned before, dual command cycle requests for the storage and retrieval sequence of the elevators lifting table and for the shuttle carrier are based on the random strategy. The detailed procedure of the above mentioned statement for the shuttle carrier and for the elevators lifting table is presented in the continuation.

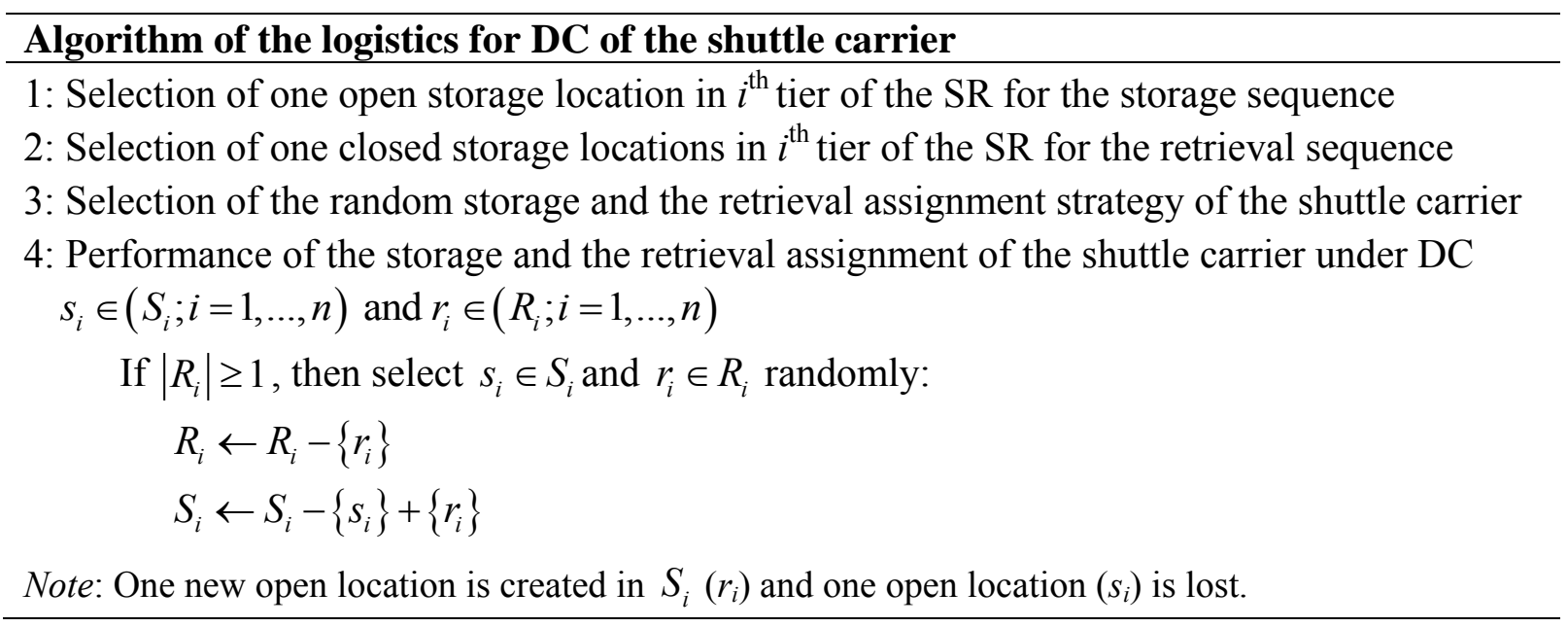


According to the algorithm of the logistics for DC of the shuttle carrier, mean dual command cycle time $T(\mathrm{DC})_{\mathrm{SCAR}}$ equals: $(i)$ mean travel time from the $\mathrm{I} / \mathrm{O}_{\text {tier } i}$ location of the SR to the random open (storage) location in the SR, (ii) mean travel time from random open (storage) location in the SR to the random close (retrieval) location in the SR and (iii) finally mean travel time from the random close (retrieval) location of the $\mathrm{SR}$ to the $\mathrm{I} / \mathrm{O}_{\text {tier } i}$ location.

Mean dual command cycle time $T(\mathrm{DC})_{\mathrm{SCAR}}$ is enlarged for all the manipulations related for totes handling (pick up and delivery times, identification time, etc.):

$$
T(\mathrm{DC})_{\mathrm{SCAR}}=4 \cdot t_{l}+t_{\mathrm{I} / \mathrm{O}_{\text {teri }}, S_{i}}+t_{S_{i}, R_{i}}+t_{R_{i}, \mathrm{~J} / \mathrm{O}_{\text {tier }}}
$$

By considering eq. (3) the throughput performance of all shuttle carriers in case of DC per hour is calculated by eq. (4):

$$
\lambda(\mathrm{DC})_{\mathrm{SCAR}}=\frac{3600}{T(\mathrm{DC})_{\mathrm{SCAR}}} \cdot k \cdot m
$$

where $k$ is 2 , due to the DC and $m=T$ due to the application of the tier-captive SBS/RS.

\section{Algorithm of the logistics for DC of the elevators lifting table}

1: Selection of one open buffer position at the $i^{\text {th }}$ tier of the SR for the storage sequence

2: Selection of one closed buffer position at the $j^{\text {th }}$ tier of the SR for the retrieval sequence

3: Selection of the random storage and the retrieval assignment strategy of the elevators lifting table

4: Performance of the storage and the retrieval assignment of the elevators lifting table under $\mathrm{DC}$

$$
\begin{aligned}
S_{i} \in( & \left.S_{i} ; i=1, \ldots, n\right) \text { and } r_{i} \in\left(R_{i} ; i=1, \ldots, n\right) \\
\text { If }\left|R_{i}\right| & \geq 1, \text { then select } s_{i} \in S_{i} \text { and } r_{i} \in R_{i} \text { randomly: } \\
R_{i} & \leftarrow R_{i}-\left\{r_{i}\right\} \\
S_{i} & \leftarrow S_{i}-\left\{s_{i}\right\}+\left\{r_{i}\right\}
\end{aligned}
$$

Note: One new open location is created in $S_{i}\left(r_{i}\right)$ and one open location $\left(s_{i}\right)$ is lost.

According to the algorithm of the logistics for DC of the elevators lifting table, mean dual command cycle time $T(\mathrm{DC})_{\text {LIFT }}$ equals: $(i)$ mean travel time from I/O location to the random open (storage) buffer position in $i^{\text {th }}$ tier of the SR, (ii) mean travel time from random open (storage) buffer position in $i^{\text {th }}$ tier of the SR to the random closed (retrieval) buffer position in $j^{\text {th }}$ tier of the SR and (iii) finally mean travel time from the random closed (retrieval) buffer position in $j^{\text {th }}$ tier of the SR to the I/O location.

Mean dual command cycle time $T(\mathrm{DC})_{\mathrm{LIFT}}$ is enlarged for all the manipulations related for totes handling (pick-up and delivery times, identification time, etc.):

$$
T(\mathrm{DC})_{\mathrm{LIFT}}=4 \cdot t_{l}+t_{\mathrm{I} / \mathrm{O}, \text { tier } i}+t_{\text {tier } i, \operatorname{tier} j}+t_{\text {tier } j, \mathrm{I} / \mathrm{O}}
$$

By considering eq. (5) the throughput performance of both (two) elevators lifting tables in case of DC per hour is calculated by eq. (6):

$$
\lambda(\mathrm{DC})_{\mathrm{LIFT}}=\frac{3600}{T(\mathrm{DC})_{\mathrm{LIFT}}} \cdot k \cdot n
$$

where $k=2$, due to the DC and $n=2$ due to the elevator with two lifting tables. 


\section{SBS/RS CASE STUDY}

In this section, main input data for the analysis are provided and discussed. Stock keeping unit represents a tote (plastic container) filled with items with the dimensions: length $l_{\text {tote }}=0.6 \mathrm{~m}$, width $w_{\text {tote }}=0.4 \mathrm{~m}$ and height $h_{\text {tote }}=0.24 \mathrm{~m}$. With regard to the tote, the storage location has the following dimensions: length (depth) of the column $l_{C O M}=0.6 \mathrm{~m}$, width of the column $w_{C O M}=0.5 \mathrm{~m}$ and height of the tier $h_{C O M}=0.5 \mathrm{~m}$. Dimensions of the SBS/RS storage rack ( $L_{S R}$ and $H_{S R}$ ) depends on the number of columns $C$ in the horizontal direction and number of tiers $T$ in the vertical direction, respectively. Velocity scenarios of the shuttle carrier and the elevators lifting table are as follows: $\left(\mathrm{vp}_{1}\right)$ stands for $v_{x}=1.5 \mathrm{~m} / \mathrm{s}, a_{x}{ }^{+}=a_{x}{ }^{-}=1.5 \mathrm{~m} / \mathrm{s}^{2}, v_{y}=1.5$ $\mathrm{m} / \mathrm{s}, a_{y}{ }^{+}=a_{y}{ }^{-}=1.5 \mathrm{~m} / \mathrm{s}^{2}$ and $\left(\mathrm{vp}_{2}\right)$ stands for $v_{x}=4.0 \mathrm{~m} / \mathrm{s}, a_{x}{ }^{+}=a_{x}{ }^{-}=3.0 \mathrm{~m} / \mathrm{s}^{2}, v_{y}=2.0 \mathrm{~m} / \mathrm{s}$, $a_{y}{ }^{+}=a_{y}{ }^{-}=1.5 \mathrm{~m} / \mathrm{s}^{2}$.

Note: velocity scenarios $\mathrm{vp}_{1}$ and $\mathrm{vp}_{2}$ are selected according to the references of material handling equipment producers and practical experiences of the authors.

Pick up and set down times $t_{l}$ for the shuttle carriers and elevators are set to 3.0 and 1.5 seconds, respectively.

As seen in Table I, nine (9) SBS/RS configurations are analysed based on three values of tiers $T(T=10, T=15$ and $T=20)$ and three values of aisles $A(A=3, A=6$ and $A=9)$. Total number of storage locations $Q$ is assumed to be approximately 10,000 storage locations [16].

Table I: SBS/RS configurations.

\begin{tabular}{|c|c|c|c|c|c|c|}
\hline $\begin{array}{c}\text { SBS/RS } \\
\text { configuration } \\
(\mathrm{RC})\end{array}$ & $\begin{array}{c}\text { Number of } \\
\text { tiers } \\
(T)\end{array}$ & $\begin{array}{c}\text { Number of } \\
\text { aisles } \\
(A)\end{array}$ & $\begin{array}{c}\text { Number of } \\
\text { columns } \\
(C)\end{array}$ & $\begin{array}{c}\text { Length of } \\
\text { the SR } \\
\left(L_{S R}\right)\end{array}$ & $\begin{array}{c}\text { Height of } \\
\text { the SR } \\
\left(H_{S R}\right)\end{array}$ & $\begin{array}{c}\text { Warehouse } \\
\text { volume } \\
(Q)\end{array}$ \\
\hline 1 & 10 & 3 & 167 & 83.50 & 5.00 & 10,020 \\
\hline 2 & 10 & 6 & 84 & 42.00 & 5.00 & 10,080 \\
\hline 3 & 10 & 9 & 56 & 28.00 & 5.00 & 10,080 \\
\hline 4 & 15 & 3 & 112 & 56.00 & 7.50 & 10,080 \\
\hline 5 & 15 & 6 & 56 & 28.00 & 7.50 & 10,080 \\
\hline 6 & 15 & 9 & 38 & 19.00 & 7.50 & 10,260 \\
\hline 7 & 20 & 3 & 84 & 42.00 & 10.00 & 10,080 \\
\hline 8 & 20 & 6 & 42 & 21.00 & 10.00 & 10,080 \\
\hline 9 & 20 & 9 & 28 & 14.00 & 10.00 & 10,080 \\
\hline
\end{tabular}

\section{ANALYSIS OF RESULTS AND DISCUSSION}

Table II summarizes mean dual command cycle time of the elevators lifting table $T$ (DC) LIFT and the shuttle carrier $T(\mathrm{DC})_{\mathrm{SCAR}}$, the throughput performance of the elevators lifting tables $\lambda(\mathrm{DC})_{\mathrm{LIFT}}$ and shuttle carriers $\lambda(\mathrm{DC})_{\mathrm{SCAR}}$.

Table II: Performance comparison of the SBS/RS.

\begin{tabular}{|c|c|c|c|c|c|c|c|c|}
\hline \multirow{3}{*}{$\mathrm{RC} i$} & \multicolumn{4}{|c|}{ Velocity profile $v p_{1}$} & \multicolumn{4}{|c|}{ Velocity profile $\mathrm{vp}_{2}$} \\
\hline & \multicolumn{2}{|c|}{ Shuttle carrier } & \multicolumn{2}{|c|}{ Elevators lifting table } & \multicolumn{2}{|c|}{ Shuttle carrier } & \multicolumn{2}{|c|}{ Elevators lifting table } \\
\hline & $\begin{array}{c}T(\mathrm{DC})_{\mathrm{SCAR}} \\
\text { (sec.) }\end{array}$ & $\begin{array}{c}\lambda(\mathrm{DC})_{\mathrm{SCAR}} \\
(\text { totes } / \mathrm{h})\end{array}$ & $\begin{array}{c}T(\mathrm{DC})_{\mathrm{LIFT}} \\
(\mathrm{sec} .)\end{array}$ & $\begin{array}{c}\lambda(\mathrm{DC})_{\mathrm{LIFT}} \\
\text { (totes/h) }\end{array}$ & $\begin{array}{c}T(\mathrm{DC})_{\mathrm{SCAR}} \\
(\mathrm{sec} .)\end{array}$ & $\begin{array}{c}\lambda(\mathrm{DC})_{\mathrm{SCAR}} \\
(\text { totes } / \mathrm{h})\end{array}$ & $\begin{array}{c}T(\mathrm{DC})_{\mathrm{LIFT}} \\
\text { (sec.) }\end{array}$ & $\begin{array}{c}\lambda(\mathrm{DC})_{\mathrm{LIFT}} \\
\text { (totes/h) }\end{array}$ \\
\hline 1 & 89.70 & 803 & 13.20 & 1091 & 53.80 & 1338 & 12.90 & 1116 \\
\hline 2 & 52.60 & 1369 & 13.20 & 1091 & 35.20 & 2045 & 12.90 & 1116 \\
\hline 3 & 40.00 & 1800 & 13.20 & 1091 & 28.90 & 2491 & 12.90 & 1116 \\
\hline 4 & 64.80 & 1667 & 15.40 & 935 & 41.40 & 2609 & 14.60 & 986 \\
\hline 5 & 40.00 & 2700 & 15.40 & 935 & 28.90 & 3737 & 14.60 & 986 \\
\hline 6 & 32.10 & 3364 & 15.40 & 935 & 24.90 & 4337 & 14.60 & 986 \\
\hline 7 & 52.60 & 2738 & 17.80 & 809 & 35.20 & 4091 & 16.40 & 878 \\
\hline 8 & 33.90 & 4248 & 17.80 & 809 & 25.80 & 5581 & 16.40 & 878 \\
\hline 9 & 27.60 & 5217 & 17.80 & 809 & 22.50 & 6400 & 16.40 & 878 \\
\hline
\end{tabular}


Shuttle based storage and retrieval system performance as a whole is presented on Fig. 2. Because of the SBS/RS is composed of the elevators lifting tables and the tier-captive shuttle carriers that are working independently from each other, the possible bottleneck is required to be found for calculating the SBS/RS system performance.

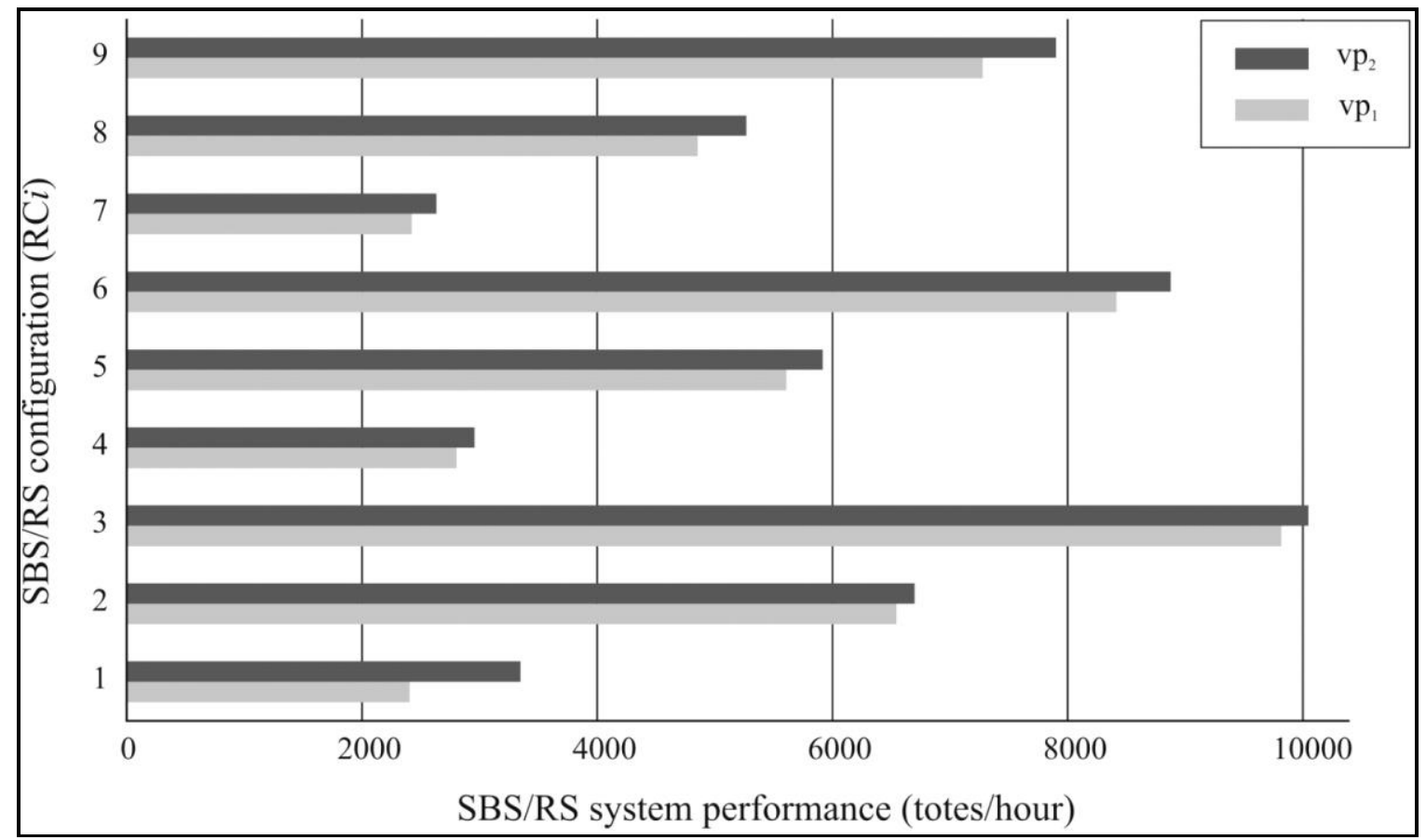

Figure 2: Shuttle based storage and retrieval system performance.

Note: The efficiency of the elevators lifting table and the shuttle carrier is calculated by $\eta=\min \left(\lambda(\mathrm{DC})_{\mathrm{SCAR}}, \lambda(\mathrm{DC})_{\mathrm{LIFT}}\right) / \max \left(\lambda(\mathrm{DC})_{\mathrm{SCAR}}, \lambda(\mathrm{DC})_{\mathrm{LIFT}}\right)$. The expected bottleneck is calculated by $\tau=\max \left(\lambda(\mathrm{DC})_{\mathrm{SCAR}}, \lambda(\mathrm{DC})_{\mathrm{LIFT}}\right.$. The throughput capacity of SBS/RS in one aisle equals $\lambda(\mathrm{DC})_{\text {aisle }}=\min \left(\lambda(\mathrm{DC})_{\mathrm{SCAR}}, \lambda(\mathrm{DC})_{\mathrm{LIFT}}\right)$. The whole SBS/RS system performance is calculated by $\lambda(\mathrm{DC})_{\mathrm{SBS} / \mathrm{RS}}=A \cdot \lambda(\mathrm{DC})_{\text {aisle. }}$.

\subsection{Shuttle carrier}

Mean dual command cycle time $T(\mathrm{DC})_{\mathrm{SCAR}}$ and consequently the throughput performance $\lambda(\mathrm{DC})_{\mathrm{SCAR}}$ depend on the number of columns $C$, number of aisles $A$ and the velocity profile $\mathrm{vp}_{i}\left(v_{x}\right.$ and $\left.a_{x}\right)$ of the shuttle carrier. Because the elevators' lifting tables are usually bottlenecks in the SBS/RS, shuttle carriers work with relatively small utilization depending on the $\mathrm{vp}_{i}$ and $\mathrm{RC} i$. The fastest double command transactions of shuttle carriers belongs to SBS/RS with relatively small number of columns $C$ (case: $A=9$; RC3, RC6 and RC9). This relationship proves to be valid for both selected velocity profiles $v_{i}$ of the SBS/RS. The opposite, the slowest double command transactions of shuttle carriers belongs to SBS/RS with relatively large number of columns $C$ (case $A=3$; RC1, RC 4 and $\mathrm{RC} 7$ ).

According to the distribution of the $T(\mathrm{DC})_{\mathrm{SCAR}}$, velocity profile $\mathrm{vp}_{i}$ has a significant impact on the mean dual command cycle time of the shuttle carrier. A decreasing tendency of $T(\mathrm{DC})_{\text {shut }}$ are observed for the velocity profile $\mathrm{vp}_{2}$ according to $\mathrm{vp}_{1}$. This relationship shows the influence of horizontal velocity $v_{x}$ and acceleration $a_{x}{ }^{+}$in accordance to the length $L_{S R}$ of the SBS/RS. Generally, the best results are achieved by shuttle carriers having fast drivers in the horizontal travelling direction.

Because the throughput capacity $\lambda(\mathrm{DC})_{\mathrm{SCAR}}$ is inversly dependent on the mean dual command cycle time $T(\mathrm{DC})_{\mathrm{SCAR}}$, the highest throughput capacity $\lambda(\mathrm{DC})_{\text {shut }}$ belongs to the 
SBS/RS with small number of columns $C$ (CASE $A=9$; RC3, RC6 and RC9). On the contrary the lowest throughput capacity $\lambda(\mathrm{DC})_{\mathrm{SCAR}}$ belongs to the SBS/RS with large number of columns $C$ (case $A=3$; RC1, RC 4 and RC7).

The throughput performance $\lambda(\mathrm{DC})_{\text {aisle }}$ of one aisle in the SBS/RS is calculated according to the expected bottleneck of the elevators lifting table or the shuttle carrier. Usually the bottleneck in the SBS/RS is the elevator, except for $\mathrm{RC} 1$ at $\mathrm{vp}_{1}$, where we have the SBS/RS configuration with large number of columns $C$ and small number of tiers $T$.

\subsection{Elevators lifting table}

Mean dual command cycle time $T(\mathrm{DC})_{\mathrm{LIFT}}$ and consequently the throughput performance $\lambda(\mathrm{DC})_{\mathrm{LIFT}}$ depend on the number tiers $T$ and the velocity profile $\mathrm{vp}_{i}\left(v_{y}\right.$ and $\left.a_{y}\right)$ of the elevators lifting table. Because the elevators lifting tables are usually a bottleneck in the SBS/RS, the elevator works with $100 \%$ efficiency. The fastest double command transactions of the elevators lifting tables belongs to SBS/RS with relatively small storage racks (case: $T=10$; $\mathrm{RC} 1, \mathrm{RC} 2$ and $\mathrm{RC} 3$ ). This relationship proves to be valid for both selected velocity profiles $\mathrm{vp}_{i}$ of the SBS/RS. The opposite, the slowest double command transactions of the elevators lifting tables belongs to SBS/RS with relatively high storage racks $H_{S R}$ (case $T=20 ; \mathrm{RC} 7$, RC8 and RC9).

\section{CONCLUSION}

In this paper, simulation analysis of the SBS/RS is presented. The simulation model of the SBS/RS is based on the tier-captive system of shuttle carriers that can travel with real velocity-time dependence in the horizontal direction. As well the elevators lifting tables that are attached on the mast are moving with real velocity-time dependence in the vertical direction. In the simulation model of SBS/RS randomized storage assignment policy and the sequencing request selection rule have been applied.

Various elements of the SBS/RS have been examined, such as the rack design of the SBS/RS, velocity of the elevators' lifting tables and the shuttle carriers in order to investigate the efficiency of the SBS/RS.

As a result of this study, we observed that the throughput capacity $\lambda(\mathrm{DC})_{\mathrm{SBS} / \mathrm{RS}}$ of the SBS/RS significantly depends on the throughput performance of the elevator $\lambda(\mathrm{DC})_{\mathrm{LIFT}}$ multiplied by the number of aisles $A$. Hence, if we decrease the travel time of lifts by decreasing the number of tiers in the system design (i.e., increasing the number of aisles), we can obtain better throughput capacity. These results can be observed in the $3^{\text {rd }}$ scenarios of both velocity profiles $\left(\mathrm{vp}_{1}\right.$ and $\left.\mathrm{vp}_{2}\right)$ in Fig. 2 .

Generally, when deciding on a SBS/RS design velocity profile of lifting mechanism, $\mathrm{vp}_{i}$ provides significant benefit in system's efficiency. For example, if we have a SBS/RS with $T=20$ and $\mathrm{vp}_{2}(\mathrm{RC} 7)$, the throughput capacity of the lift $\lambda(\mathrm{DC})_{\mathrm{LIFT}}=878$ totes/hour (Table II). Hence the system's throughput capacity depends on this value. However, the same rack design with $\mathrm{vp}_{1}, \lambda(\mathrm{DC})_{\mathrm{LIFT}}=809$ totes/hour (Table II) which is lower than the previous one. According to the extremly high throughput capacity $\lambda(\mathrm{DC})_{\mathrm{SCAR}}$ of shuttle carriers, the assumption that in each tier there is a single shuttle carrier assumption could be released (the application of non tier-captive configuration).

When we have a rack design with extremely large number of colums, this time shuttle carriers may become bottleneck if the velocity profile of them are low (see $\mathrm{RC} 1 \mathrm{of} \mathrm{vp}_{1}$ ). This time, the throughput capacity would depend on the throughput rate of the shuttle carriers. Hence, increasing the velocity profile of the shuttle carriers would increase the throughput capacity of the whole system (see RC1 of $\mathrm{vp}_{2}$ in Table II). 


\section{REFERENCES}

[1] Zollinger, H. (1999). AS/RS application, benefits and justification in comparison to other storage methods: A white paper, Automated Storage Retrieval Systems Production Section of the Material Handling Industry of America, MHIA Website, from http://www.mhia.org/industrygroups/as-rs/technicalpapers, accessed on 01-11-2014

[2] Roodbergen, K. J.; Vis, I. F. A. (2009). A survey of literature on automated storage and retrieval systems, European Journal of Operational Research, Vol. 194, No. 2, 343-362, doi:10.1016/j.ejor.2008.01.038

[3] Tompkins, J. A.; White, J. A.; Bozer, Y. A.; Tanchoco, J. M. A. (2010). Facilities Planning, John Wiley \& Sons, $4^{\text {th }}$ edition, Hoboken

[4] Malmborg, C. J. (2002). Conceptualizing tools for autonomous vehicle storage and retrieval systems, International Journal of Production Research, Vol. 40, No. 8, 1807-1822, doi: $10.1080 / 00207540110118668$

[5] Malmborg, C. J. (2003). Interleaving dynamics in autonomous vehicle storage and retrieval systems, International Journal of Production Research, Vol. 41, No. 5, 1057-1069, doi: $10.1080 / 0020754021000033887$

[6] Kuo, P.-H.; Krishnamurthy, A.; Malmborg, C. J. (2008). Performance modelling of autonomous vehicle storage and retrieval systems using class-based storage policies, International Journal of Computer Applications in Technology, Vol. 31, No. 3-4, 238-248, doi:10.1504/ IJCAT.2008.018160

[7] Fukunari, M.; Malmborg, C. J. (2009). A network queuing approach for evaluation of performance measures in autonomous vehicle storage and retrieval systems, European Journal of Operational Research, Vol. 193, No. 1, 152-167, doi:10.1016/j.ejor.2007.10.049

[8] Ekren, B. Y.; Heragu, S. S. (2011). Simulation based performance analysis of an autonomous vehicle storage and retrieval system, Simulation Modelling Practice and Theory, Vol. 19, No. 7, 1640-1650, doi:10.1016/j.simpat.2011.02.008

[9] Ekren, B. Y. (2011). Performance evaluation of AVS/RS under various design scenarios: a case study, International Journal of Advanced Manufacturing Technology, Vol. 55, No. 9-12, 1253 1261, doi:10.1007/s00170-010-3137-x

[10] Ekren, B. Y.; Heragu, S. S.; Krishnamurthy, A.; Malmborg, C. J. (2013). An approximate solution for semi-open queuing network model of an autonomous vehicle storage and retrieval system, IEEE Transactions on Automation Science and Engineering, Vol. 10, No. 1, 205-215, doi:10.1109/TASE.2012.2200676

[11] Ekren, B. Y.; Heragu, S. S.; Krishnamurthy, A.; Malmborg, C. J. (2014). Matrix-geometric solution for semi-open queuing network model of autonomous vehicle storage and retrieval system, Computers \& Industrial Engineering, Vol. 68, 78-86, doi:10.1016/j.cie.2013.12.002

[12] Roy, D.; Krishnamurthy, A.; Heragu, S. S.; Malmborg, C. J. (2012). Performance analysis and design trade-offs in warehouses with autonomous vehicle technology, IIE Transactions, Vol. 44, No. 12, 1045-1060, doi:10.1080/0740817X.2012.665201

[13] Zhang, L.; Krishnamurthy, A.; Malmborg, C. J.; Heragu, S. S. (2009). Variance-based approximations of transaction waiting times in autonomous vehicle storage and retrieval systems, European Journal of Industrial Engineering, Vol. 3, No. 2, 146-168, doi:10.1504/ EJIE.2009.023603

[14] Carlo, H. J.; Vis, I. F. A. (2012). Sequencing dynamic storage systems with multiple lifts and shuttles, International Journal of Production Economics, Vol. 140, No. 2, 844-853, doi:10.1016/j.ijpe.2012.06.035

[15] Marchet, G.; Melacini, M.; Perotti, S.; Tappia, E. (2012). Analytical model to estimate performances of autonomous vehicle storage and retrieval systems for product totes, International Journal of Production Research, Vol. 50, No. 24, 7134-7148, doi:10.1080/ $\underline{00207543.2011 .639815}$

[16] Marchet, G.; Melacini, M.; Perotti, S.; Tappia, E. (2013). Development of a framework for the design of autonomous vehicle storage and retrieval systems, International Journal of Production Research, Vol. 51, No. 14, 4365-4387, doi: $10.1080 / 00207543.2013 .778430$ 
[17] Lerher, T.; Edl, M.; Rosi, B. (2014). Energy efficiency model for the mini-load automated storage and retrieval systems, International Journal of Advanced Manufacturing Technology, Vol. 70, No. 1-4, 97-115, doi:10.1007/s00170-013-5253-x

[18] Lerher, T. (2013). Modern automation in warehousing by using the shuttle-based technology, Arent, D.; Freebush, M. (eds.), Automation Systems of the 21 ${ }^{\text {st }}$ Century: New Technologies, Applications and Impacts on the Environment \& Industrial Processes, Nova Science Publishers, New York, 51-86

[19] Smew, W.; Young, P.; Geraghty, J. (2013). Supply chain analysis using simulation, Gaussian process modelling and optimisation, International Journal of Simulation Modelling, Vol. 12, No. 3, 178-189, doi:10.2507/IJSIMM12(3)4.239

[20] Bekker, J. (2013). Multi-objective buffer space allocation with the cross-entropy method, International Journal of Simulation Modelling, Vol. 12, No. 1, 50-61, doi:10.2507/ IJSIMM12(1)5.228

[21] Berlec, T.; Kusar, J.; Zerovnik, J.; Starbek, M. (2014). Optimization of a product batch quantity, Strojniski vestnik - Journal of Mechanical Engineering, Vol. 60, No. 1, 35-42, doi:10.5545/svjme.2013.1009

[22] Erkan, T. E.; Can, G. F. (2014). Selecting the best warehouse data collecting system by using AHP and FAHP methods, Technical Gazette, Vol. 21, No. 1, 87-93 